\title{
Produção de sentidos sobre os serviços de saúde: estudo com homens da cidade de Natal-RN ${ }^{1}$
}

Production of senses in health services: a study with men in Natal-RN

Producción de sentidos respecto a los servicios de salud: estudio con hombres de la ciudad de Natal-RN

\author{
Jáder Ferreira Leite* \\ Lúcia de Fátima Carvalho \\ Magda Dimenstein ${ }^{* * *}$ \\ Ana Karenina Arraes Amorim ${ }^{* * *}$ \\ Rafaele dos Anjos Paiva ${ }^{* * * *}$ \\ Andressa Rêgo ${ }^{* * * * *}$
}

\begin{abstract}
Resumo
Este estudo analisou os sentidos produzidos por homens usuários a respeito dos serviços de atenção primária em saúde da cidade de Natal-RN. Examinamos dois contextos: unidade básica de saúde (UBS), localizada em um bairro de classe média, e uma unidade de saúde da família (USF), localizada num bairro de classe popular. Realizamos entrevistas semiestruturadas com 24 homens, sendo 12 de cada serviço. Os sentidos produzidos se vinculam às experiências vividas com os serviços, especialmente no tocante à relação profissional-usuário e à oferta de serviços. A maioria do grupo da UBS aponta para a pouca resolutividade, gerando sentidos de ineficácia do serviço. Na USF, os sentidos apresentam uma positividade em relação ao serviço, que julgamos ter relação com a natureza da ESF. A assistência à saúde do homem deve ser pensada no sentido da especificidade das suas demandas, considerando a perspectiva de gênero para se alcançar um maior conhecimento das necessidades de saúde da população masculina.
\end{abstract}

Palavras-chave: Produção de sentidos. Atenção primária. Saúde do homem. Relações de gênero.

Texto submetido em fevereiro de 2013 e aceito em maio de 2015.

1 Pesquisa realizada com apoio do CNPq, por meio do Edital Universal 2010.

Doutor em Psicologia Social pela Universidade Federal do Rio Grande do Norte (UFRN), professor adjunto do Departamento de Psicologia da UFRN. Endereço: Alameda das Mansões, 218 - T SP, ap. 802 - Bairro Candelária, Natal-RN, Brasil. CEP: 59064-740. E-mail: jaderfleite@gmail.com.

** Mestra em Psicologia pela UFRN, psicóloga da Secretaria Municipal de Saúde de Natal-RN. Endereço: Rua Monte Sinai, 1872 - Bairro Capim Macio, Natal-RN, Brasil. CEP: 59078-360. E-mail: lucifatima@uol.com.br.

*** Doutora em Saúde Mental pelo IPUB, professora titular do Departamento de Psicologia da UFRN. Endereço: Rua Vila do Mar, 222, ap. 1100 - Bairro Ponta Negra, Natal-RN, Brasil. CEP: 59090-505. E-mail: magda@ufrnet.br.

${ }^{* \cdots *}$ Doutora em Psicologia Social pela UFRN, professora adjunta do Departamento de Psicologia da UFRN. Endereço: Rua dos Tororós, 2390, ap. 1802 - Bairro Lagoa Nova, Natal-RN, Brasil. CEP: 59054-550. E-mail: akarraes@gmail.com.

${ }^{\cdots * * * *}$ Aluna do Curso de Psicologia da UFRN. Endereço: Rua Carteiro José Lucio, 4 - Bairro Neópolis, Conjunto Monte Belo, NatalRN, Brasil. CEP: 59086-365. E-mail: rafinhaanjos07@hotmail.com.

******Aluna do Curso de Psicologia da UFRN. Endereço: Rua Engenheiro Luciano Luiz de Barros, 3614 - Bairro Candelária, NatalRN, Brasil. CEP: 59064-690. E-mail: andressa_aryane@msn.com. 


\begin{abstract}
This study analyzed meanings produced by men in primary health care services used by them in Natal city. We examine two contexts: a basic health service (BHS), located in a middle-class neighborhood and a family health service (FHS), located in a popular class neighborhood. Semi-structured interviews were conducted with 24 men, 12 of each of the services. The findings produced are linked to experiences lived by the men in services, especially regarding the professional-user relation and the provision of the service offered. In BHS group, the low degree of resoluteness was appointed by the majority, generating meanings of service inefficiency. In FHS case, the meanings have a positive relationship with the service, which we believe to be related to the nature of FHS. Health care for men should be thought of in direction of their specific demands, considering gender perspective in order to achieve a greater understanding of health needs of the male population.
\end{abstract}

Keywords: Production of senses. Primary care. Men's health. Gender relations.

\title{
Resumen
}

Este estudio analizó los sentidos producidos por hombres respecto a los servicios de atención primaria de la ciudad de Natal-RN de los cuales ellos son usuarios. Actuamos en dos contextos socioeconómicos: unidad básica de salud (UBS), localizada en un barrio de clase media; y en una unidad de salud de la familia (USF), localizada en un barrio de clase popular. Realizamos entrevistas semiestructuradas a 24 hombres, siendo 12 de cada servicio. Los sentidos producidos se vinculan a las experiencias vividas en los servicios especialmente en lo que se refiere a la relación profesional-usuario y a la oferta de servicios. La mayoría del grupo de la UBS señala la poca resolutividad, generando sentidos de ineficacia del servicio. En la USF los sentidos presentan una positividad en relación al servicio, que juzgamos ser causada por la naturaleza de la ESF. La asistencia a la salud del hombre debe ser pensada en el sentido de la especificidad de sus demandas, considerando la perspectiva de género para poder alcanzar un mayor conocimiento de las necesidades de salud de la población masculina.

Palabras clave: Producción de sentidos. Atención primaria. Salud del hombre. Relaciones de género.

\section{Introdução}

tualmente o tema da saúde dos homens mostra-se em evidência tanto
em razão dos agravos à saúde vividos por estes, e que constituem sérios
problemas sanitários em nosso País, quanto pelo lançamento da Política 
Nacional de Atenção Integral à Saúde do Homem (PNAISH), em 2008. Esta foi apresentada como prioridade do governo para atender às especificidades da população masculina e enfrentar uma realidade sanitária complexa, enfatizando a necessidade de qualificar a atenção primária no sentido de dar melhores respostas às demandas de saúde apresentadas por essa população.

O objetivo geral da Política está assim descrito:

Promover a melhoria das condições de saúde da população masculina do Brasil, contribuindo, de modo efetivo, para a redução da morbidade e mortalidade dessa população, através do enfrentamento racional dos fatores de risco e mediante a facilitação do acesso às açôes e aos serviços de assistência integral à saúde (Brasil, 2008, p. 31).

O panorama geral de dados sobre a saúde dos homens aponta que estes morrem mais precocemente que as mulheres. De acordo com o Ministério da Saúde (Brasil, 2008), embora a expectativa de vida dos homens tenha aumentado de 63,20 para 68,92 anos, vivem 7,6 anos menos que as mulheres.

Gomes (2008) assinala que, em relação aos óbitos masculinos, há diferenças acentuadas de acordo com a raça/cor, devendo esse aspecto ser considerado entre seus determinantes. Agentes externos também ganham visibilidade no quadro sobre mortalidade, em que os homens morrem cinco vezes mais que as mulheres, sendo esses agentes principais os homicídios e os acidentes.

Demais estudos (Figueiredo, 2005; Gomes, Nascimento \& Araújo, 2007; Moura, Santos, Neves, Gomes e Schwarz, 2014) apontam que a procura por serviços de saúde pela população masculina dá-se principalmente por atendimentos emergenciais, tais como farmácias e pronto-socorro e, neste último caso, configura-se para os homens como uma atenção semiprofissional, de modo que, sem perda de tempo e necessidade de marcação de consulta, os homens tendem a solucionar seus problemas de saúde. Desse modo, marcase uma diferença em relação às mulheres, pois estas participam mais de ações preventivas no sistema de saúde do que os homens.

Com vistas a enfrentar essa realidade nacional, o Ministério da Saúde, por meio da PNAISH, busca orientar as açóes e serviços de saúde para a população masculina, com integralidade e equidade, primando pela humanização da atenção. Nessa direção, enfatiza a necessidade de mudanças de paradigmas no que concerne à percepção da população masculina em relação ao cuidado com sua saúde e a saúde de sua família. Entre outras ações, considera que os serviços 
públicos de saúde sejam organizados de modo a acolher e fazer com que o homem se sinta parte integrante deles (Brasil, 2008).

Lopez e Moreira (2013) destacam a PNAISH como uma tentativa de dar visibilidade às questôes de saúde dos homens, suas particularidades e demandas, já que historicamente recai sobre eles a visão de um ser homogêneo, dominante e invulnerável, portanto não demandante de cuidados em saúde.

Nesse sentido, deve-se também considerar o reduzido envolvimento de homens com tais cuidados, bem como a baixa procura por serviços de saúde como atitudes relacionadas aos modelos de masculinidades, pois parte dos problemas que envolvem tais questôes ocorrem por causa de comportamentos resultantes desses modelos. Por isso é preciso reconhecer o gênero como uma categoria ordenadora de práticas sociais que condiciona a percepção do mundo e do pensamento, funcionando como crivo por meio do qual o mundo é apreendido pelo sujeito, inclusive no campo da saúde (Couto et al., 2010; Lopez \& Moreira, 2013, Carrara, Russo \& Faro, 2009; Machado \& Ribeiro, 2012).

Outro aspecto que chama a atenção na PNAISH é uma busca de articulação com a questão da humanização em saúde. "Humanizar", de acordo com a Política Nacional de Humanização (PNH), é "ofertar atendimento de qualidade articulando os avanços tecnológicos com acolhimento, com melhoria dos ambientes de cuidado e das condições de trabalho dos profissionais" (Brasil, 2004 , p. 6). Traz, entre as suas diretrizes específicas, formas de cuidado por nível de atenção por meio de ações que visam a oferecer um tratamento mais adequado e resolutivo para as necessidades de saúde predominantes.

A proposta do Humaniza SUS na Atenção Básica (Brasil, 2009) indica que, para dar conta de suas responsabilidades, esse nível de atenção se vale de tecnologias relacionais de alta complexidade que dizem respeito aos problemas complexos do cotidiano das pessoas relacionados aos modos de viver, sofrer, adoecer e morrer no mundo contemporâneo. Nesse sentido, aponta a necessidade dos profissionais se aproximarem dos saberes, práticas, crenças e afetos dos usuários com o desenvolvimento de estratégias de comunicação que potencializem a relação entre ambos.

Ao refletirem sobre a política de humanização, Jungues et al. (2012) pontuam que a humanização diz de uma postura ética voltada às ações em saúde aliada à eficácia tecnológica, englobando na terapêutica as dimensões subjetivas e socioculturais que revestem o processo saúde-doença.

Simões, Rodrigues, Tavares e Rodrigues (2007), com base num enfoque sobre a humanização na atenção básica, assinalam a necessidade de alterações 
de natureza administrativa, subjetiva e do próprio modo de tratar os usuários como sujeitos ativos e portadores de direitos e não mais como alvo de práticas meramente assistenciais. Os autores destacam ainda os impasses entre um sistema de saúde ideal apresentado em seus princípios e diretrizes e a realidade vivida no cotidiano dos serviços.

Além disso, em razão da diversidade de situações vivenciadas na atenção básica, mostra-se evidente a necessidade de ela também estar conectada a outros setores da saúde, outras políticas públicas e movimentos sociais, potencializando a capacidade de resposta dos serviços de saúde em termos de resolutividade das demandas. Por resolutividade estamos considerando a capacidade de dar uma solução aos problemas do usuário do serviço de saúde de forma adequada, no local mais próximo de sua residência ou encaminhando-o aonde suas necessidades possam ser atendidas conforme o nível de complexidade (Portal Sisreg, 2004).

O processo de resolutividade pode, ainda, fazer referência ao acesso ao serviço e à maneira como se deu o acolhimento, por terem uma relação direta com as respostas dadas pelo serviço. De acordo com Ramos e Lima (2003, p. 29), o acesso indica aspectos que vão desde a distância de moradia do usuário ao equipamento de saúde, passando pelos meios utilizados para seu deslocamento, tempo de espera, tratamento recebido até a priorização de situações de urgência. Já o acolhimento está focado em como o profissional sente e lida com as necessidades dos usuários, direcionando-o para o sistema com vistas a responder suas demandas.

Dessa forma, indagamos se os homens que buscam serviços de saúde estão se reconhecendo como atores de uma atenção integral e de um cuidado humanizado. Assim, esta investigação teve por objetivo analisar os sentidos produzidos por homens sobre os serviços de atenção primária por eles utilizados, bem como seu posicionamento em relação às respostas dadas pelos serviços às suas demandas de saúde.

Os estudos sobre a produção de sentidos filiam-se à corrente do construcionismo social, tal com aparece no campo da Psicologia social, segundo Spink e Frezza (2000), Spink e Medrado (2000) e Spink (2010). A sua principal característica é tratar a realidade, seus sujeitos e objetos como produções sóciohistóricas. Portanto o conhecimento dessa realidade depende, especialmente, do modo como a acessamos. Como destacam Spink e Frezza (2000, p. 28): "Só apreendemos os objetos que se nos apresentam a partir de nossas categorias, convenções, práticas, linguagem: enfim, de nossos processos de objetivação".

A produção de sentidos é, nessa perspectiva, uma forma de produção de conhecimento que se gera no cotidiano das interações sociais, por meio das práticas discursivas. Segundo Spink e Medrado (2000): 
O sentido é uma construção social, um empreendimento coletivo, mais precisamente interativo, por meio do qual as pessoas - na dinâmica das relaçóes historicamente datadas e culturalmente localizadas - constroem os termos a partir dos quais compreendem e lidam com as situações e fenômenos a sua volta. (p. 41).

Nessa abordagem, a linguagem aparece como uma importante forma de mediar a produção de sentidos, desde que seja compreendida como linguagem em uso, ou seja, como prática social, dotada de performatividade, tomada em termos de suas condições de uso e de produção em dado contexto social. Portanto o elemento mediador da produção de sentidos são as práticas discursivas. Tais práticas são definidas como "as maneiras pelas quais as pessoas, por meio da linguagem, produzem sentidos e posicionam-se em relaçôes sociais cotidianas" (Spink, 2010, p. 27). Assumem para os sujeitos um caráter ativo tanto na elaboração de conhecimentos quanto no posicionamento em práticas sociais do cotidiano. A autora acrescenta que, diferentemente do discurso que tende a revelar os conteúdos de regularidade linguística ou aqueles em que a linguagem se institucionalizou, por meio das práticas discursivas, é possível compreender o campo das ressignificações, das rupturas, portanto, da heterogeneidade.

A possibilidade de situar as práticas discursivas em termos de uma regularidade ou de heterogeneidade aparece numa abordagem temporal (Spink, 2010; Spink $\&$ Medrado, 2000). Ou seja, esses autores situam o trabalho com o contexto discursivo de produção de conhecimentos em três tempos, a saber: "O tempo longo, que marca os conteúdos culturais, definidos ao longo da história da civilização; o tempo vivido, das linguagens sociais aprendidas pelos processos de socialização; e o tempo curto, marcado pelos processos dialógicos" (Spink \& Medrado, 2000, p. 51). O tempo curto de que falam os autores é o da polissemia, ou seja, das produções discursivas em que os tempos anteriores se articulam e se atualizam com o tempo presente.

Desse modo, ensejamos, ao investigar os sentidos que os homens atribuem a serviços de atenção primária de saúde na cidade do Natal-RN, contribuir com novas reflexões no âmbito acadêmico e profissional que auxiliem na efetivação das políticas de humanização e de saúde para os homens, e nas quais estes possam desenvolver formas de autocuidado, tornando-se protagonistas desse processo, bem como gerar uma reflexão que traga novos olhares para a desnaturalização dos lugares tradicionais de gênero, de modo a fazer falar a polissemia que reveste esse campo da vida social. 


\section{Aspectos metodológicos da investigação}

Esta investigação é parte da pesquisa "Os sentidos da saúde numa perspectiva de gênero: um estudo comparativo entre homens da cidade do Natal/RN" (CNPq Processo no 478242/2010-7). Realizamos a etapa de campo, durante o ano de 2011, por meio de visitas a uma unidade básica de saúde (UBS) de um bairro de classe média e a uma unidade de saúde da família (USF) de um bairro de classe popular da cidade do Natal-RN, com a finalidade de identificação dos participantes. Estes foram abordados na sala de espera da unidade e demonstraram e registraram consentimento livre em participar da investigação.

\subsection{Participantes do estudo}

A partir da abordagem na sala de espera das unidades, foram selecionados e entrevistados 24 homens, sendo 12 de cada serviço de saúde. Os critérios que orientaram a escolha dos participantes foram: ter idade entre 25 e 59 anos (faixa etária definida pela PNAISH) e ser residente no bairro em que está situada a unidade de saúde.

O perfil dos participantes está apresentado conforme a tabela a seguir.

Tabela 1. Perfil socioeconômico dos participantes do estudo por serviço de saúde

\begin{tabular}{l|c|c|c|c|l|l}
\hline \multicolumn{1}{|c|}{ Participante } & Idade & Estado civil & Escolaridade & Ocupação & \multicolumn{1}{c}{$\begin{array}{c}\text { Renda } \\
\text { individual }\end{array}$} \\
\hline \multicolumn{5}{|c|}{ GRUPO I - UNIDADE BÁSICA DE SAÚDE (UBS) } \\
\hline P1 & 44 & Divorciado & $\begin{array}{c}\text { Superior } \\
\text { completo }\end{array}$ & $\begin{array}{c}\text { Servidor } \\
\text { municipal }\end{array}$ & $2.0000,00$ \\
\hline P2 & 53 & Casado & $\begin{array}{c}\text { Médio } \\
\text { completo }\end{array}$ & Comerciante & $1.000,00$ \\
\hline P3 & 35 & Casado & $\begin{array}{c}\text { Fundamental } \\
\text { completo }\end{array}$ & Autônomo & $2.500,00$ \\
\hline P4 & 28 & Casado & $\begin{array}{c}\text { Fundamental } \\
\text { incompleto }\end{array}$ & Corretor de \\
veículos & $1.000,00$ \\
\hline P5 & 33 & Casado & $\begin{array}{c}\text { Médio } \\
\text { completo }\end{array}$ & Comerciário & $2.000,00$ \\
\hline P6 & 34 & Solteiro & $\begin{array}{c}\text { Médio } \\
\text { completo }\end{array}$ & $\begin{array}{c}\text { Técnico em } \\
\text { informática }\end{array}$ & 900,00 \\
\hline P7 & 25 & Solteiro & $\begin{array}{c}\text { Superior } \\
\text { incompleto }\end{array}$ & Estudante & 600,00 \\
\hline P8 & 55 & Casado & $\begin{array}{c}\text { Fundamental } \\
\text { incompleto }\end{array}$ & Ambulante & 545,00 \\
\hline P9 & 44 & Casado & $\begin{array}{c}\text { Fundamental } \\
\text { completo }\end{array}$ & Porteiro & 700,00 \\
\hline
\end{tabular}




\begin{tabular}{|c|c|c|c|c|c|}
\hline P10 & 54 & Solteiro & $\begin{array}{l}\text { Fundamental } \\
\text { incompleto }\end{array}$ & Desempregado & 350,00 \\
\hline P11 & 32 & Solteiro & $\begin{array}{l}\text { Fundamental } \\
\text { incompleto }\end{array}$ & Desempregado & Sem renda \\
\hline P12 & 32 & Solteiro & $\begin{array}{c}\text { Médio } \\
\text { completo }\end{array}$ & Comerciante & $1.500,00$ \\
\hline \multicolumn{6}{|c|}{ GRUPO II - UNIDADE DE SAÚDE DA FAMÍLIA (USF) } \\
\hline P13 & 32 & Solteiro & $\begin{array}{l}\text { Fundamental } \\
\text { incompleto }\end{array}$ & Autônomo & 700,00 \\
\hline P14 & 32 & Solteiro & $\begin{array}{l}\text { Médio } \\
\text { completo }\end{array}$ & $\begin{array}{c}\text { Auxiliar de } \\
\text { serviços gerais }\end{array}$ & 250,00 \\
\hline P15 & 53 & Casado & Analfabeto & Aposentado & 630,00 \\
\hline P16 & 26 & União estável & $\begin{array}{c}\text { Fundamental } \\
\text { incompleto }\end{array}$ & Mecânico & 750,00 \\
\hline P17 & 48 & União estável & $\begin{array}{l}\text { Fundamental } \\
\text { incompleto }\end{array}$ & Vendedor & $2.000,00$ \\
\hline P18 & 33 & União estável & $\begin{array}{c}\text { Fundamental } \\
\text { incompleto }\end{array}$ & Padeiro & 800,00 \\
\hline P19 & 45 & Casado & $\begin{array}{l}\text { Fundamental } \\
\text { incompleto }\end{array}$ & Vigia & $1.000,00$ \\
\hline P20 & 25 & União estável & $\begin{array}{l}\text { Fundamental } \\
\text { incompleto }\end{array}$ & Comerciante & 500,00 \\
\hline P21 & 39 & União estável & $\begin{array}{l}\text { Médio } \\
\text { completo }\end{array}$ & Gari & 600,00 \\
\hline P22 & 25 & União estável & $\begin{array}{l}\text { Fundamental } \\
\text { incompleto }\end{array}$ & $\begin{array}{l}\text { Auxiliar de } \\
\text { marceneiro }\end{array}$ & 750,00 \\
\hline P23 & 26 & Solteiro & $\begin{array}{l}\text { Fundamental } \\
\text { incompleto }\end{array}$ & $\begin{array}{l}\text { Ajudante de } \\
\text { pedreiro }\end{array}$ & 150,00 \\
\hline P24 & 58 & União estável & $\begin{array}{l}\text { Médio } \\
\text { completo }\end{array}$ & Autônomo & 800,00 \\
\hline
\end{tabular}

Fonte: elaborado pelos autores.

\subsection{Produção dos dados}

Foram realizadas entrevistas semiestruturadas, em uma sala disponibilizada pela direção das unidades, sendo utilizado recurso de gravador de áudio para registro, mediante autorização prévia dos participantes. $\mathrm{O}$ roteiro de entrevista foi estruturado pelos seguintes blocos:

a) perfil socioeconômico dos participantes;

b) investigação dos sentidos da saúde; e

c) exploração dos sentidos sobre os serviços de saúde. Neste último bloco, foco deste estudo, questionamos os entrevistados sobre sua relação com os 
serviços, que relatassem como se deu o atendimento ou atendimentos e o desdobramento dado às suas demandas (resolutividade - em termos de acesso e acolhimento), como se sentiram e que posicionamento apresentaram em relação a estes.

As entrevistas foram transcritas e analisadas com base na perspectiva das práticas discursivas (Spink \& Medrado, 2000; Spink, 2010). A análise buscou identificar os sentidos sobre os serviços com base nos eixos: acesso e acolhimento.

\section{Os sentidos sobre os serviços de saúde}

\subsection{O acesso aos serviços}

A busca dos homens entrevistados pelos serviços foi motivada tanto por demandas pessoais quanto para acompanhar familiares (esposa e filhos) em consultas. Ao serem indagados sobre as experiências de atendimento na unidade, os entrevistados ressaltaram tanto aspectos de satisfação quanto de descontentamento com o serviço.

As insatisfaçôes, no que diz respeito ao acesso, foram elencadas pela demora em ser atendidos, filas, limitação de fichas para atendimento/dia, horário de funcionamento da unidade incompatível com o trabalho e a falta de informação adequada por algum profissional que pudesse recepcioná-los, ausência de profissionais específicos para as demandas dos homens:

Porque, assim... Pra gente ir pra um especialista, você tem que passar primeiro no postinho pra pegar uma requisição e aí tem toda aquela... Aquela demora pra poder ser atendido, tudo isso. Como eu tou muito ocupado, agora, dedicando exclusivamente pra faculdade, então tou esperando as férias pra poder dar essa iniciativa, tomar essa iniciativa de ir fazer um tratamento, isso no SUS ou não (P7).

É. É a demanda que é muita pra pouco médico. Aí tem que pegar... Aí é só dez fichas, aí quando a gente não chega cedo, que perde, aí tem que vir outro dia (P14).

Estudo conduzido por Schraiber et al. (2010) também destacou aspectos semelhantes, principalmente no tocante à falta de adequação do horário de funcionamento dos serviços para a população masculina que trabalha. Foi assinalada, ainda, a ausência de profissionais especializados para o atendimento de suas demandas, como urologistas. Machado e Ribeiro (2012), numa 
investigação sobre os sentidos de homens jovens acerca dos serviços de saúde, também identificaram tais questôes, destacando ainda a falta de insumos e profissionais como impedimento para seu melhor acesso.

Esses aspectos não somente acabam levando os homens a retornar à unidade seguidas vezes na busca de ter sua demanda atendida, mas provocam afastamento, exatamente por se converterem em barreira ao atendimento. Acrescente-se a isso que a desistência se torna mais comum entre homens, já que os serviços de saúde estão mais preparados para atendimento de mulheres e crianças, e os homens, geralmente tomados por um imaginário social de invulnerabilidade, não reconhecem a atenção básica como espaço para acolhimento de suas demandas. São falas que refletem a dificuldade de acesso aos serviços, e os sentidos que foram sendo produzidos em torno destes se pautaram numa descrença em relação à sua resolutividade.

O conjunto dessas insatisfações foi apontado, em grande maioria, pelos entrevistados da unidade básica de saúde. Já os homens da unidade de saúde da família, em sua totalidade, apontaram, de modo positivo, o acesso e o atendimento prestado pela equipe de profissionais:

E: Você acha que o problema que o senhor levou pra lá foi resolvido?

P: Foi, foi, porque eles resolvem. É... Toda semana, se o paciente se dirigir a uma dessas unidades, indo pra um dentista, o dentista resolve, porque se o dentista dispōe na unidade de todos os produtos necessários para resolver a situação do paciente, ele, com certeza, resolve, sem nenhum problema. Agora depende deles terem o material suficiente para realizar o tratamento (P13).

Aqui é bom. Minha mulher sempre vem aqui. Eu fiz o meu primeiro atendimento também nesse... Proveniente da dor de cabeça, tem mais ou menos uma semana ou duas (P16).

É necessário destacar que essa unidade de saúde, por nortear suas ações pela Estratégia de Saúde da Família (ESF), tem uma atuação mais ampliada em relação à unidade básica de saúde, que apresenta ações mais restritas no que se refere à assistência prestada. A ESF

É entendida como uma estratégia de reorientação do modelo assistencial, operacionalizada mediante a implantação de equipes multiprofissionais em unidades básicas de saúde. Estas equipes são responsáveis pelo acompanhamento de um número definido de famílias, localizadas em uma área geográfica delimitada. As equipes atuam com açôes de promoção da saúde, prevenção, recuperação, reabilitação de doenças e agravos mais frequentes, e na manutenção da saúde desta comunidade (Brasil, 2012, p. 1). 
Assim, considerando tal reorientação no modelo assistencial, parece que o acompanhamento e responsabilização pelas famílias na própria comunidade podem ter resultado em um estabelecimento positivo de vínculo das equipes com os usuários, a exemplo da presença dos agentes comunitários de saúde nas residências. Esses fatores foram apontados como geradores de satisfação em relação ao cuidado recebido, além de estar facilitando a resolutividade das necessidades apresentadas. Nesses termos, o acesso promovido com base nas ações territoriais e o vínculo construído com os profissionais foram mediadores importantes na elaboração de sentidos que expressaram positividade em relação ao serviço.

\subsection{O acolhimento}

Ao explorarmos a relação dos homens com os profissionais dos serviços, o atendimento de suas necessidades e as respostas dadas às suas demandas, muitas falas foram pautadas de modo comparativo a experiências anteriores, tanto nos serviços investigados quanto em outros já buscados pelos participantes. Nesses termos, houve uma variedade de posicionamentos sobre os profissionais, as relações estabelecidas e o modo como as demandas foram encaminhadas.

Um dos entrevistados da UBS relatou uma boa relação estabelecida com uma enfermeira, fato determinante para o sucesso de seu tratamento (isso ocorreu em outra unidade de saúde), o que fez destacar a diferença do cuidado desta com a UBS. Afirmou não achar tal unidade resolutiva, mas avaliou positivamente o serviço prestado por outra unidade à qual recorreu e, em especial, dessa profissional com quem manteve um bom vínculo:

Essa pessoa se interessa muito, é uma pessoa que se interessa muito pelos meus problemas. É como se fosse... Sabe? Como tem gente boa, tem gente ruim. No caso, essa enfermeira ela é uma pessoa ótima. Quem presta socorro no meu medicamento é ela. Muito atenciosa, acompanha... O caso quando piora, ela procura encaminhar a gente pro médico e tal (P8).

O relato feito pelo participante (P8) sobre o acolhimento prestado por essa profissional denotou uma postura para o atendimento das necessidades de saúde do usuário. Expressou, em suas várias definições, uma ação de aproximação, um "estar com" e um "estar perto de", ou seja, uma atitude de inclusão" (Brasil, 2010).

Por outro lado, foi apontada a forma deficitária de atender por parte dos médicos tanto da UBS quanto da USF: 
Ele é meio assim sabe? [referindo-se ao médico] Não olha pra cara da pessoa. Você fica falando e ele fica... Aí já pergunta o que é? Aí a pessoa diz, aí ele já vai logo passando o remédio. Porque o médico devia escutar melhor o paciente, né. Saber o que é que tem realmente, e ficar ligado, né. Aí a pessoa vem e... né. Só ele não, tem vários, né. Que é assim... Agora eu não sei por quê. Pressa, sei lá, tem outros cantos pra ir... Quanto mais rápido pra ele, melhor, né. A mulher mesmo, às vezes, veio uma vez e não gostou (P9).

É... Algumas outras vezes o doutor $\mathrm{X}$ atendia, mas não era... Assim... muito... com vontade né? Ele não atendia com vontade, o doutor X. É... doutor Y ele também atendia, mas não era aquele atendimento aconchegante, uma coisa maravilhosa (P13).

Ramos e Lima (2003) destacam a abordagem do médico como algo bastante valorizado e que o exame físico é um dos critérios que, entre outras coisas, pode determinar a escolha do profissional e do serviço. O exame físico criterioso e detalhado demonstra o interesse do profissional pelo usuário e, para este, maior precisão no diagnóstico e tratamento.

Tais autores afirmam ainda que a busca por profissionais competentes para o atendimento e a confiança na experiência e capacidade dos membros da equipe de saúde influenciam fortemente a escolha quanto ao serviço a ser procurado. A escolha baseada nesses critérios ocorre mesmo quando o acesso a uma unidade de saúde exige um maior deslocamento.

Percebemos ainda nas falas acima que a relação entre a satisfação do usuário e a competência e interesse demonstrado pelo profissional foi um dos fatores que contribuíram para que a produção de sentidos sobre o serviço de saúde contemplasse sua dimensão de resolutividade. Nelas estão apontados os termos a partir dos quais os participantes informaram o modo como poderiam e gostariam de ser atendidos, em direção a um acolhimento na perspectiva da humanização (Jungues et al., 2012; Gomes, Rebello, Nascimento, Deslandes \& Moreira, 2011). Fica claro como a interação discursiva usuário-profissional reflete na forma em que é vivenciada a utilização do próprio serviço de saúde.

Fica evidente também que a qualidade do cuidado e o vínculo estabelecido entre o usuário e serviço, e/ou com determinado profissional, com base numa relação de confiança, faz com que o usuário permaneça utilizando o serviço, mesmo que se mude para outro bairro. Além disso, a boa qualidade da relação usuário/profissional pode ser determinante para a corresponsabilização daquele em relação a seu processo saúde/doença, conforme propicia uma maior autonomia ao usuário. 
Nessas falas também emergiram questôes específicas a respeito da relação com o profissional médico, única categoria mencionada pelos entrevistados apresentando uma postura de pouco interesse no cuidado que, como foi exposto anteriormente, pode comprometer a permanência do público no serviço, assim como a corresponsabilização em relação ao processo saúde/doença do usuário. A esse respeito, Schraiber et al. (2010) afirmam que existe uma semelhança no funcionamento dos serviços de atenção primária, em que as consultas são rápidas e os profissionais médicos estão mais preocupados em oferecer uma pronta resposta, reduzindo o mais possível a complexidade do atendimento. Além disso, tomam decisões voltadas a condutas já conhecidas e centradas na terapêutica de patologias, ocorrendo muitos encaminhamentos, pedidos de exames e quase sempre há uma indicação de remédios.

Por outro lado, um elemento que foi destacado pelos usuários e que se interpôs no atendimento de suas necessidades de saúde diz respeito a esses encaminhamentos para outros serviços (realização de exames e especialistas), o que muitas vezes eram significados como uma quebra no atendimento, já que podiam levar muito tempo para sua realização. Os entrevistados da USF, nesse caso, apresentaram falas favoráveis ao acolhimento prestado pelas equipes de saúde da família, mas quando as necessidades precisavam de outros níveis de complexidade, os homens tenderam a um posicionamento crítico, já que implicava, em certa medida, realizar grandes descolamentos, espera prolongada para atendimento e certa impessoalidade na relação com os profissionais, diferentemente do vínculo já estabelecido com as equipes da atenção básica.

Aqui é importante destacar que a produção de sentidos sobre os serviços de saúde, mesmo que focados para a atenção básica neste estudo, esteve ligada às experiências dos homens com a rede de saúde em geral. Nas entrevistas, foi bastante comum os homens de ambos os grupos deslocarem suas falas em relação à atenção básica e acessarem suas vivências com outros serviços, notadamente os de atenção especializada (hospitais, policlínicas e unidades de pronto atendimento).

Esse deslocamento permitiu-nos destacar dois pontos: um primeiro se refere ao fato de que a atenção especializada acaba sendo mais visada pelos homens. Recorrer a serviços especializados informa, em grande medida, o nível de agravos à saúde dos homens.

O segundo ponto nos permitiu observar dois eixos utilizados e articulados pelos participantes no tocante à produção de sentidos sobre os serviços de saúde: as experiências diretas com estes e os repertórios que circulam socialmente em relação ao Sistema Único de Saúde (SUS) e que foram apropriados pelos entrevistados. O modo como o SUS apareceu em suas falas foi visto, de modo geral, com base numa ideia de ineficácia: 
Eu fui, dei entrada no posto... Mas nunca saiu, nunca sai essas coisas, esse negócio do SUS... Aí também fiquei aguardando, aguardando... e deixando pra lá, deixando... E até hoje não fiz ainda, mas eu vou cuidar por que esperar pelo SUS pode complicar [refere-se ao problema de uma hérnia] (P2).

A produção de sentido sobre os serviços de saúde, mediada tanto pelos repertórios sobre o SUS quanto pelas experiências vividas no curso da história pessoal dos usuários, remeteu-nos à divisão de tempos históricos proposta por Spink e Medrado (2000) para trabalhar as práticas discursivas em diferentes níveis. Percebemos que os sentidos atribuídos ao SUS e o consequente posicionamento em relação aos serviços de saúde procurados pelos homens se relacionaram, nesse caso, ao tempo vivido, aparecendo como resultado de um aprendizado e sendo traduzido para uma linguagem que tem sido comumente compartilhada socialmente. O sentido de ineficácia atribuído ao SUS refletiu, em parte, as experiências vivenciadas por esse usuário, como também refletiu diretamente na maneira dele se posicionar e dar sentido ao sistema público de saúde. A assistência pública parece não ser algo confiável, em que possa esperar por possibilidades efetivas de ajuda. Associam-se a isso as inúmeras matérias veiculadas nas mídias televisivas e jornalísticas que se convertem em repertórios sociais aos quais os sujeitos recorrem na elaboração de sentidos sobre os serviços públicos de saúde:

É... Das pessoas que... Onde a pessoa vai dar entrada na papelada, recebe as pessoas bem, o paciente bem, né. Eu digo assim, é a demora pra se fazer um exame, é isso. Mas, o atendimento das pessoas... Resolve, resolve. Demora, mas resolve, né. Agente tem que esperar mesmo, não tem pra onde correr... Só que você sabe, fica demorando porque o SUS é assim mesmo (P24).

A expressão "por que o SUS é assim mesmo" reflete um sentido de certo descrédito para com o Sistema, que passa a ser naturalizado e compartilhado em diversas instâncias do tecido social (usuários, trabalhadores e meios de comunicação), produzindo realidades discursivas muitas vezes utilizadas para desqualificar a potência de que se reveste o SUS.

\section{Considerações finais}

Esta investigação, direcionada aos sentidos produzidos por homens sobre serviços de saúde da atenção básica, tomando como eixo o tema da resolutividade, possibilitou a identificação de alguns entraves no que se refere ao acesso aos 
serviços: existência de filas e falta de fichas para atendimento, falta de insumos, incompatibilidade entre o horário de trabalho e de funcionamento da unidade de saúde, ausência de profissionais voltados para as especificidades masculinas.

Vale ressaltar que tais entraves foram mais considerados pelo grupo de participantes da unidade básica de saúde. Já os homens da unidade de saúde da família identificaram bem menos obstáculos para acessar esse serviço. Acreditamos que essa diferença entre os sentidos dados ao acesso ao serviço esteja, em parte, vinculada ao modelo de atenção adotado pela ESF, que consegue ter um alcance maior e mais integrado por meio das equipes de saúde da família.

No que tange ao acolhimento, foi destacada, em ambos os grupos, a relação estabelecida com os profissionais, especialmente a figura do médico. Os homens apontaram a necessidade de um acolhimento humanizado, com vistas a serem tratados com mais atenção e tendo suas necessidades de saúde atendidas. Em contraponto a essas experiências, os homens discursavam sobre outras vivências em que se sentiram acolhidos pelos profissionais e de como esse tratamento possibilitou resolutividade em suas demandas.

Para a produção de sentidos em torno dos serviços de saúde, os homens recorreram tanto às experiências vividas na rede de serviços como um todo (para além da unidade de saúde) como aos repertórios socialmente compartilhados a respeito do SUS. A combinação desses elementos promoveu sentidos que, a depender de como se deu o processo de acesso e acolhimento no serviço, poderiam fazer referência positiva e de vinculação com o serviço. Do contrário, as concepções socialmente naturalizadas sobre o SUS aliadas às experiências não exitosas acabaram por produzir sentidos de ineficácia sobre o serviço.

Ao se refletir a respeito da temática "homem e saúde" com base nos sentidos atribuídos pelos homens usuários, fica evidente a necessidade de mudanças na realidade da assistência e essas devem ser pensadas em direção das especificidades das demandas dessa clientela.

Com base no que foi analisado na pesquisa, percebe-se que há muitos desafios para que se alcance tal condição. Fica claro que as mudanças devem ser amplas e também específicas dentro dos serviços, em relação aos aspectos gerencias e organizacionais, nas estruturas físicas, melhores condições de trabalho para promover uma maior articulação entre os avanços tecnológicos e um acolhimento humanizado, com uma especial ênfase na relação profissional-usuário.

Outro aspecto de fundamental importância para contemplar as diferentes demandas de saúde dos homens na assistência seria uma melhor familiarização dos profissionais e dos gestores no que concerne às discussões de gênero, para 
que adquiram uma maior sensibilidade aos problemas trazidos pelos homens ao serviço (Gomes, 2008; Schwarz, 2012).

Por fim, entendemos que o acesso e o acolhimento humanizado são elementos essenciais para a qualidade do serviço, pois contribuem para a procura e a satisfação dos usuários, especialmente no caso da população masculina que ainda necessita construir uma cultura de busca por esses serviços sob a ótica da prevenção. Com isso, acreditamos que os sentidos sobre a rede de serviços, ao se configurarem com base na resolutividade (acesso e acolhimento), poderão permitir uma maior vinculação dos homens a esses serviços. 


\section{Referências}

Brasil (2004). Ministério da Saúde. Humaniza SUS: Política Nacional de Humanização: a bumanização como eixo norteador das práticas de atenção $e$ gestão em todas as instâncias do SUS. Secretaria-Executiva, Núcleo Técnico da Política Nacional de Humanização. Brasília: Ministério da Saúde.

Brasil (2008). Ministério da Saúde. Política de atenção integral à saúde do homem: principios e diretrizes. Secretaria de Atenção à Saúde. Departamento de Ações Programáticas Estratégicas. Brasília: Ministério da Saúde.

Brasil (2009). Ministério da Saúde. O Humaniza SUS na atenção básica. Secretaria de Atenção à Saúde. Política Nacional de Humanização da Atenção e Gestão do SUS. Brasília: Ministério da Saúde. Recuperado a partir de http://www. redehumanizasus.net/sites/default/files/10_0381_final_o_humanizasus_na_ ab.pdf

Brasil (2010). Ministério da Saúde. Acolhimento nas práticas de produção de saúde. Secretaria de Atenção à Saúde. Núcleo Técnico da Política Nacional de Humanização Brasília: Ministério da Saúde.

Brasil (2012). Ministério da Saúde. Política Nacional de Atenção Básica. Brasília: Ministério da Saúde (Série E. Legislação em Saúde).

Carrara, S., Russo, J. \& Faro, L. (2009). A política de atenção à saúde do homem no Brasil: os paradoxos da medicalização do corpo masculino. Physis - Revista de Saúde Coletiva, 19 (3), 659-678.

Couto, M. T., Pinheiro, T. F., Valença, O., Machin, R., Silva, G. S. N., Gomes, R. ..., \& Schraiber, L. B. (2010). O homem na atenção primária à saúde: discutindo (in)visibilidade a partir de gênero. Interface - Comunicação, Saúde, Educação, 14(33), 257-270.

Figueiredo, W. (2005). Assistência à saúde dos homens: um desafio para os serviços de atenção primária. Ciência e Saúde Coletiva, 10(1), 105-109.

Gomes, R. (2008). Sexualidade masculina, gênero e saúde. Rio de Janeiro: Fiocruz.

Gomes, R., Nascimento, E. F. \& Araújo, F. C. (2007). Por que os homens buscam menos os serviços de saúde do que as mulheres? As explicações de homens com baixa escolaridade e homens com ensino superior. Cadernos de Saúde Pública, 23 (3), 565574 . 
Gomes, R., Rebello, L. E. F. S., Nascimento, E. F., Deslandes, S. F. \& Moreira, M. C. N. (2011). A atenção básica à saúde do homem sob a ótica do usuário: um estudo qualitativo em três serviços de Rio de Janeiro. Ciência e Saúde Coletiva, 16(11), 45134521 .

Jungues, J. R., Barbiani, R., Fernandes , R. B. P., Prudente, J., Schaefer, R., \& Kolling, V. (2012). O discurso dos profissionais sobre a demanda e a humanização. Saúde e Sociedade, 21(3), 686-697.

Lopez, S. B. \& Moreira, M. C. N. (2013). Políticas Nacionais de Atenção Integral à Saúde de Adolescentes e Jovens e à Saúde do Homem: interlocuções políticas e masculinidade. Ciência \& Saúde Coletiva, 18(3), 743-752.

Machado, M.F. \& Ribeiro, M.A.T. (2012). Os discursos de homens jovens sobre o acesso aos serviços de saúde. Interface - Saúde, Educação, Comunicação, 16(41), 34355.

Moura, E. C., Santos, W., Neves, A. C. M., Gomes, R. \& Schwarz, E. (2014). Atenção à saúde dos homens no âmbito da Estratégia Saúde da Família. Ciências e Saúde Coletiva, 19(2), 429-438.

Portal Sisreg. (2004). Recuperado a partir de http://www.portalsisreg.epm.br/conteudo/ principios.htm.

Portaria n. 1.944 (2009, 27 agosto). Brasília: Ministério da Saúde.

Ramos, D. D. \& Lima, M. A. D. S. (2003). Acesso e acolhimento aos usuários em uma unidade de saúde de Porto Alegre, Rio Grande do Sul, Brasil. Cadernos de Saúde Pública, 19 (1), 27-34.

Schraiber, L. B., Figueiredo, W. S., Coutro, M. T., Pinheiro, T. F., Machin, R., . . \& Valença, O. (2010). Necessidades de saúde e masculinidades: atenção primária no cuidado aos homens. Cadernos de Saúde Pública, 26(5), 961-970.

Schwarz, E. (2012). Reflexões sobre gênero e a Política Nacional de Atenção Integral à Saúde do Homem. Ciência \& Saúde Coletiva, 17(10), 2579-2588.

Simões, A. L. A., Rodrigues, F. R., Tavares, D. M. S. \& Rodrigues, L. R. (2007). Humanização na saúde: enfoque na atenção primária. Texto e Contexto - Enfermagem, 16(3), 439-444.

Spink, M. J. P. (2010). Linguagem e produção de sentidos no cotidiano. Rio de Janeiro: Centro Edelstein de Pesquisas Sociais. 
Spink, M. J. P. \& Frezza, R. M. (2000). Práticas discursivas e produção de sentidos: a perspectiva da Psicologia social. In M. J. P. Spink (Org.), Práticas discursivas e produção de sentido no cotidiano: aproximaçâes metodológicas. (pp. 17-40). São Paulo: Cortez.

Spink, M. J. P. \& Medrado, B. (2000). Produção de sentido no cotidiano: uma abordagem teórico-metodológica para a análise das práticas discursivas. In M. J. P. Spink (Org.), Práticas discursivas e produção de sentido no cotidiano: aproximaçôes metodológicas. (pp. 41-61). São Paulo: Cortez. 